\title{
Jeux de mains
}

\author{
F. Klotz \\ C Springer-Verlag France 2013
}

En 2013, l'OMS lance la campagne pour sauver des vies : «L'hygiène des mains »!

Vous me direz « encore »! Je vous dirai « toujours»!

En Asie du Sud-Est on se dit bonjour en saluant d'un signe de tête et en joignant les mains, dans les pays méditerranéens et en Afrique Noire la poignée de main est conviviale et la refuser est un signe de dédain.

La transmission manu portée des agents pathogènes est connue depuis plus d'un siècle et demi et la lutte contre celle-ci doit se poursuivre intensément.

Lorsqu'il y eu l'épidémie de SRAS, il était indiqué aux habitants des grandes villes chinoises de supprimer poignées de mains et accolades. Au milieu du XIX ${ }^{\mathrm{e}}$ siècle, Semmelweis démontrait la transmission par les mains sales de la fièvre puerpérale dans les maternités de Vienne. Il affirmait que «le processus pathogène » passait de femme en femme par les touchers vaginaux réalisés par les mains non lavées des étudiants en médecine qui revenaient de la salle de dissection des cadavres.

La main, ce merveilleux outil qui sert à tout : du geste élémentaire aux travaux les plus minutieux et les plus sophistiqués, du geste qui tue au geste qui crée. Cet outil est dangereux car il est un énorme réservoir de germes. Les doigts passent en un instant de la bouche, au nez, au mouchoir, à l'anus, à la poignée de porte, à la rampe d'escalier, à celle des transports en commun, à la main des autres, aux aliments, aux animaux domestiques, aux soins d'un enfant ! C'est la danse effrénée et diabolique des bactéries, des virus et des parasites.

Une enquête épidémiologique sur cinq cas de typhoïde chez des habitués d'une baraque à sandwichs parisienne, nous rappelle l'importance de cette contamination manu portée. Le péril fécal utilise ce mode de transmission : choléra, toxi-infections alimentaires bactériennes ou virales, protozooses intestinales, oxyurose se propagent par les mains sales.

De manière plus accessoire, car essentiellement transmis par voie aérienne et par les aérosols réalisés par les gouttelettes de pflüge, les virus de la grippe et de la bronchiolite peuvent être transmis par les mains sales, persistant plusieurs heures dans le mucus séché sur les mains et les ustensiles de la vie courante.

La vigilance et le recours systématique aux mesures d'hygiène et aux solutions antiseptiques hydro-alcooliques sont le meilleur rempart contre les infections nosocomiales dans les services de soins intensifs et le personnel médical les exercent de mieux en mieux. Les infections sévères intrahospitalières dues à des bactéries multirésistantes de type Acinetobacter baumanii nécessitent une hygiène draconienne du personnel et la redécouverte de matériaux comme le cuivre pour la réalisation de ce qui est en contact répété avec les mains (rambardes, poignées de porte et de placards).

La population, même dans les pays à niveau d'hygiène élevé, est trop souvent ignorante, négligente et oublieuse des règles élémentaires. Le lien hygiène-santé, s'il paraît évident, n'est pas assez enseigné aux enfants et répété aux parents. Des messages d'hygiène et de santé publique doivent être diffusés par les médias audiovisuels, rappelant la nécessité de se laver les mains et de renouveler ce geste surtout en cas d'épidémie et dans les familles de malade, en détaillant ses modalités.

Les instituteurs et les enseignants des « sciences de la vie et de la terre » devraient systématiquement intéresser leurs élèves à l'importance de la transmission manu portée et à l'apprentissage de l'hygiène corporelle, participant ainsi avec le corps médical au combat contre le péril fécal par des " initiatives de lavage des mains » pour lutter contre les maladies diarrhéiques responsables de mortalité infantile. Les épidémies de gastro-entérites sont meurtrières dans les régions à bas niveau d'hygiène. Les progrès thérapeutiques $\mathrm{du} \mathrm{XXI}^{\mathrm{e}}$ siècle ne doivent pas faire oublier les règles d'hygiène élémentaires, tout particulièrement l'usage du savon après le passage aux toilettes et avant les repas, car la main est coupable de transmission d'agents pathogènes même dans des environnements qui paraissent sécurisés.

Faut-il prohiber "la poignée de main », ce passage de relais microbien? Ce serait une bonne chose, mais un tel geste culturel ne peut disparaître facilement !

Il faudrait lancer un concours mondial pour la remplacer. L'Asie du Sud-Est a une longueur d'avance ! 